\title{
Conociendo a Aby Warburg
}

\author{
Luis Eugenio Campos ${ }^{l}$
}

\begin{abstract}
RESUMEN: Aby Warburg es la oculta figura creadora de los estudios de iconología. Personaje indiscutido, ha sido retomado en los últimos años a partir de la reedición de sus obras y de numerosos estudios que posicionan su figura intelectual y los impactos que tuvo su método de aproximación a las imágenes, específicamente aquellos que hablaban del renacimiento del paganismo. Conceptos como pathosformeln, sobrevivencias de la antigüedad, accesorios en movimiento y el análisis histórico, psicológico y contextual de la producción cultural de las imágenes, son hoy característicos de una todavía novedosa manera de entender el estudio de la iconología.
\end{abstract}

PALABRAS CLAVES: Iconología. Iconografía. Aby Warburg.

\section{Como encontrar a Aby Warburg}

Como antropólogo aficionado al estudio de las imágenes y a la fotografía, siempre me han interesado los libros que contienen imágenes. Los atlas, libros de fotografías, grabados, todas aquellas producciones en donde lo que se ve tiene mayor preponderancia sobre lo que se lee. Es en esas circunstancias en que me encontré por primera vez con Aby Warburg en la edición castellana de El renacimiento del Paganismo (2005). Edición de tapa dura, con una bella sobrecubierta en donde aparece el detalle de uno de sus principales motivos, la Ninfa. Lo que me llamó entonces la atención del texto fueron dos cosas: primero su título, extrañamente esta vez no modificado por los traductores. En segundo lugar, la Ninfa y las imágenes desplegadas en su interior, entre ellas, la de un Aby Warburg de mediana edad, vestido a la usanza vaquera del oeste norteamericano y posando junto a un indígena pueblo. Sin saber cómo ni por qué, sin duda se acercaba a la imagen de los más clásicos antropólogos de la época. Unos meses después, pasando por otra librería me encontré con un pequeño libro verde/azul que en su lombada con letras blancas decía Warburg. El ritual de la serpiente (2004). Al interior nuevamente la imagen de Warburg con el nativo americano y un subtítulo encantador para cualquier

\footnotetext{
${ }^{1}$ Doctor en Antropología. Escuela de Antropología Universidad Academia de Humanismo Cristiano. Investigador Principal ICIIS, Conicyt/Fondap/15110006. E-mail: luiseugenicampos@gmail.com.
} 
antropólogo: Imágenes de la Región de los Indios Pueblo de Norteamérica. En la contraportada se explicaba que el libro era producto de una conferencia dictada en 1923 y que fue parte de sus últimos días de residencia en una institución psiquiátrica en la cual Warburg fue internado por varios ańos con un diagnóstico cercano a la esquizofrenia. Esta obra fue un verdadero ritual de sanación que le habría permitido, al igual que a los indios Hopi, controlar las fuerzas violentas y paganas que poblaban su interior y volcarlas hacia fuera, dominándolas, a través de su razón. El pequeño libro, más seductor a la lectura que el pesado Renacimiento del Paganismo y con una temática netamente antropológica, encantaba, además, por la sensible historia de su protagonista.

La lectura del Ritual de la Serpiente me llevó entonces a desempolvar el Paganismo y descubrir los hechos biográficos básicos de una vida que desde su inicio hasta el fin se tińe de aquella formula patética tan importante para el análisis del propio Warburg. Cabe destacar aquí la introducción realizada por Kurt W. Forster y los detalles íntimos de la vida de historiador del arte, entre ellos el relato de cómo Aby Warburg a la edad de 13 años y siendo heredero y primogénito de una gran fortuna proveniente de una familia de banqueros alemanes, decide renunciar a su herencia a cambio del compromiso de sus hermanos menores de comprarle todos los libros que quisiera y financiar sus investigaciones, promesa cumplida a cabalidad por la familia.

Por otro lado, el libro El Ritual de la Serpiente conduce a conocer la enfermedad que aqueja a Aby Warburg, su locura, esquizofrenia, o su trastorno maniaco depresivo. No se puede dejar de leer en este sentido el texto que aparece coautorado por Ludwig Binswanger y Aby Warburg y que corresponde al relato hecho por el famoso psiquiatra a cargo de su tratamiento, titulado La curación Infinita (2007). En el mismo libro se pueden encontrar las cartas que intercambiaron con Warburg y otros miembros de su familia, apreciándose de manera cruda y compleja el difícil momento que debió pasar el historiador cuando entre los años 1918 y 1925 se declara de manera evidente su enfermedad. Todo lo anterior entrega una base para enfrentar los textos biográficos, ya sea el libro más conocido escrito por Ernst Gombrich denominado Aby Warburg una Biografía Intelectual (1992); y el más nuevo y reivindicador de la figura del maestro, La Imagen Superviviente (2009), de George Didi-Huberman. De ahí en adelante es sólo sorprenderse por las obras del todavía poco conocido historiador e intentar sumergirse en la resurrección que se ha propuesto principalmente en los primeros años del siglo XXI, a más de 70 años de su muerte. 


\section{Guía Para leER a Aby Warburg}

La lectura de Aby Warburg se debe realizar a partir de sus textos fundamentales, sin dejar de lado lo que plantean sus comentaristas, siendo sin duda un autor del que se han desprendido muchas más ideas y conceptos de los que el mismo se habría imaginado. En honor a su figura comenzaré por los textos escritos por el propio Warburg, para concluir con aquellos que hablan de sus conceptos, de sus alcances, proyecciones, análisis y de su especial manera de ver la cultura de las imágenes.

\section{A. Los TEXTOS FUNDAMENTALES DE WARBURG}

La primera compilación fue presentada en 1932, tres años después de su muerte, por sus más cercanos colaboradores, Gertrud Bing y Fritz Saxl y fue llamada Escritos Seleccionados. Con posterioridad una versión ampliada de esta selección pasará a ser conocida como El Renacimiento del Paganismo. En este gran volumen fueron reunidos los textos que volvieron a Warburg un pensador reconocido en Europa de principios del siglo XX, tales como El Nacimiento de Venus y la Primavera de Sandro Botticelli (1893); La última voluntad de Francesco Sassetti (1907); Durero y la Antigüedad italiana (1905); Arte y astrología internacional en el Palazzo Schifanoia de Ferrara (1912); y Profecía pagana en palabras e imágenes en la época de Lutero (1920). Si bien en la compilación se señalan algunos textos escritos con posterioridad a 1920, la mayor parte de ellos corresponde a la producción del historiador antes de su debacle mental. En estos textos se aprecia cómo Aby Warburg va entrando lentamente en un campo no transitado, identificando en diversas pinturas, grabados, tapices y esculturas, los principales conceptos que lo harán famoso con posterioridad, pero que fundamentalmente conducirán al historiador a inventar una aproximación metodológica que dará origen a la llamada iconología.

Luego de esta compilación la mayor parte de los estudios de Warburg se remiten a 1923, año en que presenta en el sanatorio Bellevue en Kreuzlingen, Suiza, la conferencia que hoy conocemos como El Ritual de la Serpiente. Una primera versión de ésta fue publicada en alemán en el año 1928, también bajo la atenta mirada de Fritz Saxl y de Gertrud Bing. En el año 1988, 50 años después, y patrocinada por el Instituto Warburg, se publicará la versión completa de la conferencia. La versión castellana cuenta, además, con un epílogo explicativo de Ulrich Raulff, mientras que la edición norteamericana es introducida y comentada en un ensayo interpretativo por Michael P. 
Steinberg. En ambas ediciones el título del texto presentado es Imágenes de los indios pueblo de Norteamérica y el texto mantiene la estructura de una conferencia.

El último texto, también publicado de manera póstuma, es tal vez el menos conocido, pero el que más impacto ha causado en la actualidad, sobre todo por ser identificado como el antecedente más claro de los actuales estudios iconológicos. Me refiero a Atlas Mnemosyne (2010), publicado por primera vez en alemán en el año 2000 bajo el nombre Der Bilderatlas MNEMOSYNE (2000), edición llevada a cabo por Martin Warnke. Corresponde específicamente a la producción de Warburg una vez que regresa de la clínica y comienza su reincorporación al trabajo del Instituto Warburg, espacio recreado por Fritz Saxl a partir de las indicaciones que a lo largo de los años había dado Warburg y que contemplaba en la época una gran biblioteca, salas de exposiciones y medios técnicos para la presentación de materiales audiovisuales. Es precisamente la mezcla de todos estos elementos los que van a llevar a Warburg a plantear la construcción de un análisis de la cultura con énfasis en las imágenes, las que debían estar desplegadas en paneles que eran constantemente montados y desarmados con la finalidad de buscar las conexiones que debían tener las imágenes, identificando en ellos los conceptos que eran parte fundamental de su trabajo, tales como los accesorios en movimiento, las fórmulas patéticas y las sobrevivencias del pasado.

\section{B. LOS RESUCITADORES DEL PADRE DE LA ICONOLOGÍA}

Para conocer de Warburg no basta con la lectura de sus textos. Tampoco recomiendo lo contrario, quedarse sólo con los comentaristas. Reseñaré aquí algunos que me parecieron más inspiradores para guiar la comprensión de su lectura. Algunos de ellos ya los he mencionado, como la increíble historia de su curación infinita o la biografía intelectual que realiza Gombrich, trabajando directamente sobre los papeles de Warburg confiados a él por Bing y Saxl. Pero sin duda va a ser George Didi Huberman con el texto La Imagen Superviviente (2009) el que va a llegar más lejos con la reivindicación del maestro. Es la visión más directamente comprometida, en la que también trabajando sobre los archivos de Warburg, va a construir una mirada distinta acerca del historiador de la cultura y del arte. Según Didi-Huberman para Warburg “[...] cada imagen, es el resultado de movimientos que provisionalmente han sedimentado o cristalizado en ella. Estos movimientos la atraviesan de parte 
a parte y cada uno de ellos tiene una trayectoria -histórica, antropológica, psicológica- que viene de lejos y que continúan más allá de ella. Tales movimientos nos obligan a pensar la imagen como un momento energético o dinámico [...]" (DIDI-HUBERMAN, 2009, p.34-35).

Influenciado por una mirada psicoanalítica y con un conocimiento envidiable de ciencias sociales, filosofía y arte, Didi-Huberman escribe una verdadera vindicación de Warburg. Critica a Gombrich el haber dejado de lado el período de locura de Warburg. Señala, además, que habiéndosele encomendado la tarea de rescatar la obra del autor alemán, termina escribiendo un texto que más se aproxima a una visión personal que a una caracterización de la extensa obra de Warburg. Es más, insinúa que tanto Gombrich como el propio Panofsky habrían en sí distorsionado y minimizado los logros de Aby Warburg, de manera tal que sus propias propuestas, sin duda hoy por todos reconocidas, fueran más originales de lo que realmente eran. En este sentido no verían en Warburg al iniciador de los estudios de iconología, sino más bien a un erudito evolucionista que tuvo grandes ideas, pero al cual su vida personal, cargada de dolencias, le habría impedido llegar a un buen fin intelectual.

En este enmarañado de reflexiones, Didi-Huberman se da la inmensa tarea de trabajar con comentadores y directamente sobre las obras de Warburg, habiendo también tenido acceso al material inédito sobre el que Gombrich habría trabajado a principios de los años treinta. Destacan en este texto de DidiHuberman las relaciones intelectuales de Warburg con importantes autores de la antropología como E.B.Tylor, fundamental para la noción de sobrevivencia de lo antiguo, y también de Franz Boas, con quién se habría encontrado en su viaje a los Estados Unidos. Hay que recordar que para esta travesía Warburg toma contacto con la gente del Smithsonian Museum, específicamente con destacados etnógrafos, aproximándose así al trabajo de Boas, sobre todo en lo relativo del análisis de la cultura material que el etnólogo venía realizando con máscaras y enseres decorativos de los Kwakiutl y otros pueblos nativos de Norteamérica.

Por último, el propio Didi-Huberman hará mención de Warburg en otros textos, siempre reivindicando la figura del autor alemán, destacando el volumen titulado Ante el tiempo. Historia del Arte y anacronismo de la Imágenes (2008), en el cual intenta aplicar los presupuestos teóricos básicos y los alcances de la teoría warburiana; y su último libro sobre Warburg, Atlas ¿Cómo llevar el mundo a cuestas? (2010) texto derivado de la exposición del mismo nombre que se presentó en España el 2010 y que recorrió Europa en el 2011 y 
en la que se solicitó a diversos artistas el poder replicar el modelo para trabajar las imágenes que Warburg presenta en el Atlas Mnemosyne, principalmente el trabajo de imágenes a partir de la presentación de paneles explicativos que se convierten en placas en que una imagen ilumina a la otra para encontrar los sentidos de la cultura. Este inmenso trabajo implicó la aplicación más sistemática de la obra de Warburg y forma parte de las últimas reivindicaciones que se han realizado por este autor.

Otro de los textos destacados del último tiempo es el de Rafael García Mahíques en su libro Iconografía e Iconología (2008) en que se reseña la tradición de los estudios iconológicos fundados principalmente en la presentación de la figura de Warburg. Lo mismo se puede plantear del texto de José Emilio Burucúa, Historia, arte, cultura. De Aby Warburg a Carlo Ginzburg (2007) en el cual se traza nuevamente la genealogía de estudios sobre las imágenes en donde Warburg opera como iniciador y catalizador de una aproximación histórica cultural a las imágenes.

En la bibliografía de este artículo se encontrará el gran cúmulo de textos en inglés y espańol que últimamente han surgido sobre Warburg, llevando su pensamiento incluso a lugares insospechados como el trabajo de Philippe-Alain Michaud Aby Warburg and the Image in Motion (2007) en donde se llevan los temas del maestro a la imagen en movimiento; o los trabajos de Settis y de Ivars, ambos del 2010, en los que se describe de manera específica lo que significó la Biblioteca Warburg y toda la odisea que se ejecutó de manera tal de trasladar el material desde Hamburgo a Londres en 1933, para pasar luego a constituir uno de los más importantes centros de estudio de las imágenes, como viene a ser el actual Instituto Warburg.

\section{SUS PRINCIPALES CONCEPTOS}

La supervivencia de lo antiguo o el renacimiento desde la antigüedad es uno de sus principales conceptos y tiene relación con el título de su compilación más conocida, El Renacimiento del Paganismo. Esta idea ya presente en su tesis sobre los trabajos de Botticelli el Nacimiento de Venus y La Primavera, plantea analizar a través de las imágenes, los mecanismos por medio de los cuales una idea visual, un accesorio, un detalle, transita por el tiempo, apareciendo y desapareciendo de las representaciones visuales, influido por elementos de cultura, política, economía, como también por cuestiones religiosas. 
Cuando se refiere a paganismo en principio da cuenta de la retomada de aspectos grecolatinos que se da en el Renacimiento, si bien con posterioridad a su viaje a Estados Unidos, ampliará su referente de paganismo a los pueblos no civilizados. Hay que aclarar que este tránsito de las imágenes y las ideas si bien se plantea en un contexto inicial evolucionista, va a tender en definitiva al tema de la supervivencia en términos de una anulación del tiempo y lo que el autor entiende como una necesaria conciliación de los opuestos, en este caso, paganismo/civilización, como también la conciliación de otras polaridades como las derivadas de la articulación de diversas realidades culturales en el sincretismo religioso y en las tradiciones estéticas de distintas sociedades.

Como derivado de lo anterior, Warburg siempre llamó la atención sobre la importancia de los detalles en el arte decorativo y en los motivos de lo artístico, lo que él llama accesorios en movimiento. Al respecto, su trabajo sobre la Ninfa y sus accesorios, sobre todo lo relativo a los peinados y otros adornos, hablan de la importancia que tenían los detalles y cómo el seguimiento de estos podía llegar a explicar o dar cuenta de las conexiones históricas que había en determinadas imágenes y poder así caracterizar la continuidad que permitía, por ejemplo, el renacimiento del paganismo. Este esfuerzo será una de las principales guías de influencia que permitan dar fuerza al nuevo proyecto iconológico que se formaría a partir de los trabajo de Warburg y que lo ayudaría a sintetizar la idea de Pathosformeln o Fórmulas Patéticas, basada en una teoría de la empatía o proyección sentimental trabajada por Vischer y que hablaba del cómo algunos artistas al querer decir algo con sus obras, se basaban en formulas emotivas originadas en trabajos anteriores, obtenidos de los modelos de antigüedad y que iban apareciendo a lo largo de los años en diversas obras de arte. Era entonces tarea del historiador descubrir estas fórmulas y trazar así su genealogía de manera tal de orientarse a dar cuenta de una psicología de la cultura o de los pueblos a partir de sus imágenes, sus recuerdos y su memoria visual.

Todo esto quedará plasmado en uno de sus últimos aportes, el Proyecto Menmosyne, cuya finalidad era la construcción de un gran Atlas que se apoyara en el corpus existente de imágenes de occidente y su choque con el paganismo a lo largo del mundo. Este se sustentaba en la idea de una memoria visual que trascendía las generaciones e incluso las culturas, pero que siempre estaba marcada por referentes históricos precisos y no como un arquetipo jungiano, más allá de la existencia. Esta memoria visual se montaba en los diversos paneles que trabajó Warburg en sus últimos años de vida, y que obligaban a 
tratar una temática a partir de la vecindad de imágenes, sobre un panel de tela negra, lo que permitía trascender los tiempos y las unidades culturales en los análisis y ofrecer una aproximación técnica y metodológica al estudio del arte como una psicología de la cultura.

Warburg propone así una psicología de la cultura construida a partir del mosaico infinito de imágenes que los pueblos van produciendo a lo largo del tiempo y que permiten explicar y conocer, a su vez, a la misma cultura. La utilización de las imágenes para la realización de una arqueología de la cultura, permite visualizar y caracterizar la imbricación de los tiempos, no a partir de una teoría de los arquetipos, sino a través de los contactos históricos reales, por medio de la memoria social de las imágenes, describiendo las soluciones a los problemas iconográficos actuales, a partir de lo que se encuentra en el depositario de elementos de la memoria social.

\section{Conclusión: Aby Warburg o el RENACimiento deSDe la ANTigüedad}

Si bien Warburg estuvo presente en la instalación de la iconología moderna y ha sido mencionado permanentemente desde los primeros ańos del siglo XX, su figura terminó siendo eclipsada por autores posteriores como Gombrich y el propio Panofsky. Sin restarle méritos a estos destacados intelectuales que sin duda posicionaron y sistematizaron el estudio de las imágenes en el siglo XX, la recuperación de los trabajos de Warburg ha servido para dar una visión más compleja y entender de mejor forma el proyecto de la iconología. La proliferación de textos sobre Warburg a partir del año 2000 muestra con claridad que había aspectos en Aby Warburg que no estaban presentes en los autores citados.

Para los lectores de habla castellana se ha realizado en el último tiempo un esfuerzo sostenido por editar en español gran parte de este material, incluyendo textos de algunos de sus discípulos y seguidores más fieles, como es el caso de Edgar Wind, quién desde Inglaterra apoyó en vida el trabajo de Warburg y, quizás en mayor propiedad, los textos de Fritz Saxl, ayudante personal de Warburg y una de las personas que mejor conoció al intelectual alemán. Saxl acompañó a su mentor por sus devaneos y lo apoyó en todo momento, haciéndose cargo personalmente del ya conformado Instituto Warburg mientras Aby permanecía internado por su enfermedad mental. En este sentido vale la pena aproximarse al texto La vida de las imágenes (1989), 
el que considero uno de los más fieles retratos de la aplicación del método warburgiano para trabajar con imágenes.

Esta resurrección se ha dado en diversos países, sobre todo en Italia, Alemania y España, e incluso en Argentina con el trabajo de José Emilio Burucúa (2007), lo que ha permitido trazar la genealogía intelectual de este importante autor y fijar sus grados de influencia a partir de sus trabajos iniciales de fines del siglo XIX, hasta la presencia de sus ideas en autores tan importantes como el propio Saxl, Gombrich, Panofsky, Ginzburg y Agamben. Con estos antecedentes va quedando más claro el importantísimo papel que jugó Warburg en el pensamiento iconológico y la vigencia de sus ideas que pueden ser aplicadas en la actualidad a un sinnúmero de campos y que vienen a complejizar y a hacer entender de mejor forma aquello que hemos conocido a través de sus discípulos.

\title{
Agradecimientos
}

Investigación financiada por el Centro Interdisciplinario de Estudios Interculturales e Indígenas-ICIIS, Código de Proyecto: CONICYT/ FONDAP/15110006 y por el Proyecto FONDECYT 1110878, Altares de la Virgen de La Tirana.

CAMPOS, Luis Eugenio. Meeting Aby Warburg. Trans/Form/Ação, Marília, v. 37, n. 1, p. 151-162, Jan./Abr., 2014

\begin{abstract}
Aby Warburg is the hidden figure that created the study of the iconology. This remarkable character has been taken up again, because of the new editions of her works and numerous studies, which positioned her intellectual figure and all the impacts that her method of approximation to images had, specifically those that talked about the renaissance of paganism. Concepts like pathosformel, the survivals of the antiquity, movement accessories and the analysis of the history, psychology and context of the production of images culture, are today characteristic of a still new way to understand the iconologist word.
\end{abstract}

KEYWORDS: Iconology. Iconography. Aby Warburg. 


\section{Bibliografía}

AGAMBEN, Giorgio. Ninfas. Valencia, España: Pre-Textos, 2010.

AGAMBEN, Giorgio. La potencia del pensamiento. Buenos Aires: Adriana Hidalgo, 2007.

BELTING, Hans. Antropología de la imagen. Buenos Aires: Katz, 2007.

BINSWANGER, Ludwig; WARBURG, Aby. La curación infinita. Buenos Aires: Adriana Hidalgo, 2007.

BURCKHARDT, Jacob. Del paganismo al cristianismo. México: FCE, 2006.

BURUCÚA, José Emilio. Historia, arte, cultura. De Aby Warburg a Carlo Ginzburg. Buenos Aires: FCE, 2007.

BURUCÚA, José Emilio. Historia y ambivalencia. Ensayos sobre arte. Buenos Aires: Biblos, 2006.

CARNIA SLOVIN, Francesca. Obsessed by Art. Aby Warburg: his life and his legacy. USA: Xlibris, 2006.

CESTELLI GUIDI, Benedetta; MANN, Nicholas (Ed.). Photographs at the Frontier. Aby Warburg in América 1895-1896. Londres: Merrel Holberton; Warburg Institute, 1998.

DIDI-HUBERMAN, Georges. Atlas ¿Cómo llevar el mundo a cuestas? Madrid: Museo Nacional Centro de Arte Reina Sofía, 2010.

DIDI-HUBERMAN, Georges. Lo que vemos, lo que nos mira. Buenos Aires: Manantial, 2010.

DIDI-HUBERMAN, Georges. La imagen superviviente. Historia del arte y tiempo de los fantasmas según Aby Warburg. Madrid: Abada, 2009.

DIDI-HUBERMAN, Georges. Ante el tiempo. Historia del arte y anacronismo de las imágenes. Buenos Aires: Adriana Hidalgo, 2008.

FREEDBERG, David. El poder de las imágenes. Madrid: Cátedra, 2010.

GARCÍA MAHÍQUES, Rafael. Iconografía e iconología. V. 2 Cuestiones de método. Madrid: Encuentro, 2009.

GARCÍA MAHÍQUES, Rafael. Iconografía e iconología. V. 1. La historia del arte como historia cultural. Madrid: Encuentro, 2008.

GINZBURG, Carlo. Mitos, emblemas, indicios. Morfología e Historia. Barcelona: Biblioteca Económica Gedisa, 2008.

GOMBRICH, Ernst. Elsentido del orden. Estudio sobre la psicología de las artes decorativas. Tailandia: Phaidon, 2010.

GOMBRICH, Ernst. La historia del Arte. China: Phaidon, 2010. 
GOMBRICH, Ernst. Arte e ilusión. Estudio sobre la psicología de la representación pictórica. China: Phaidon, 2002.

GOMBRICH, Ernst. Aby Warburg. Una biografía intelectual. Madrid: Alianza, 1992.

GOMBRICH, Ernst. Tributos. Versión cultural de nuestras tradiciones. Buenos Aires: FCE, 1991.

GOMBRICH, Ernst. Aby Warburg. An intellectual biography. Chicago: The University of Chicago Press, 1986.

MICHAUD, Philippe-Alain. Aby Warburg and the Image in Motion. New York: Zone Books, 2007.

PANOFSKY, Erwin. Estudios sobre iconología. Madrid: Alianza, 2010.

PANOFSKY, Erwin. El significado de las artes visuales. Madrid: Alianza, 1979.

RAMPLEY, Matthew. The Remembrance of Things Past. On Aby M. Warburg and Walter Benjamin. Alemania: Harrassowitz Varlag, 2000.

RUSSELL, Mark. Between tradition and modernity. Aby Warburg and the public purposes of art in Hamburg, 1896-1918. USA: Berghahn Books, 2007.

SAXL, Fritz. La vida de las imágenes. Madrid: Alianza, 1989.

SETTIS, Salvatore. Warburg continuatus. Descripción de una biblioteca. Barcelona: La Central - Museo Nacional Centro de Arte Reina Sofía, 2010.

STEINBERG, Michael P. Images from the region of the Pueblo Indinas of North America. USA: Cornell University Press, 1995.

WARBURG, Aby. Atlas Mnemosyne. Madrid: Akal, 2010.

WARBURG, Aby. Sandro Botticelli. Madrid: Casimiro, 2010.

WARBURG, Aby. El renacimiento del paganismo. Aportaciones a la historia cultural del Renacimiento europeo. Madrid: Alianza, 2005.

WARBURG, Aby. El ritual de la serpiente. México: Sexto Piso, 2004.

WOODFIELD, Richard ed. Art history as cultural history. Warburg's projects. Holanda: G +B Arts International, 2001.

YVARS, José Francisco. Imágenes cifradas. La biblioteca magnética de Aby Warburg. Barcelona: Elba, 2010.

Submissão: 21/04/2013

Aceito em: 29/07/2013 